\title{
Research on Application Effect of Mixconverter in Cement Concrete Pavement
}

\author{
Wang Tao ${ }^{1}$, Liu Tao ${ }^{1}$, Liang Xiayi ${ }^{1}$, Wei Hanxin ${ }^{1}$, Zheng Zhigang ${ }^{1}$, He Yunwu ${ }^{2}$, Xiao Xin ${ }^{3 *}$ \\ ${ }^{1}$ Shenzhen Yuetong Construction Engineering Co., Ltd, 518019, Shenzhen, China \\ ${ }^{2}$ Shenzhen Tagen<group> Co., Ltd, 518034, Shenzhen, China \\ ${ }^{3}$ Foshan University, 528000, Foshan, China
}

\begin{abstract}
In order to improve the strength of cement concrete pavement and reduce pavement cracking, the application effect of the hydration reaction enhancer Mixconverter in cement concrete pavement was studied by testing the compressive strength, bending strength, crack resistance and chloride ion permeability of concrete indoors. The test results show that the addition of Mixconverter to concrete can significantly improve the compressive and flexural strength of concrete, effectively prevent the expansion of plastic shrinkage and cracking of concrete, and significantly reduce the chloride ion diffusion coefficient. Finally, the test road pavement further proves the improvement effect of Mixconverter on concrete strength and cracking.
\end{abstract}

\section{Introduction}

Cement concrete pavement is a main form of high-grade highway and it is extensively utilized. However, with the increase of the use time, the difference of the application area and the change of the environment, considerable cement concrete pavements have been damaged due to a variety of reasons and fail to reach the expected service life. Some of these are caused by the failure of the early strength of the cement concrete to meet the requirements $[1,2]$, and some are caused by the cracking of the cement concrete [3-5]. The addition of additives to the cement concrete to extend the service life of cement concrete pavement is the simplest and most practical method. Given this, this paper adopted the Evergreen concrete hydration reaction enhancer Mixconverter to improve the conventional cement concrete mix design and improve the performance of the conventional cement concrete, so as to achieve the effect of extending the service time of cement concrete pavement.

\section{Testing process}

\subsection{Testing materials}

The 42.5 ordinary Portland cement is used with its main performance indicators shown in Table 1; The fine aggregate is medium sand from Xiang River; The course aggregate is graded gravel with a particle size of 5 to $31.5 \mathrm{~mm}$. Mixconverter is an opaque white, nonpetroleum-based, non-toxic, odorless, easy to use, neutral and environmentally friendly colloidal liquid matrix. The addition of Mixconverter can promote the hydration of concrete, enhance the bonding force between cement slurry and aggregate, and improve the density of concrete, thereby improving the overall strength and durability of concrete. Its technical indicators are shown in Table 2.

Table 1 Main performance indicators of cement

\begin{tabular}{|c|c|c|c|c|c|c|c|}
\hline \multirow{2}{*}{$\begin{array}{c}\text { Fineness } \\
\mathrm{m}^{2} / \mathrm{kg}\end{array}$} & Soundness & \multicolumn{2}{|c|}{ Setting time (min) } & \multicolumn{2}{|c|}{$\begin{array}{c}\text { Flexural strength } \\
(\mathrm{MPa})\end{array}$} & \multicolumn{2}{c|}{$\begin{array}{c}\text { Compressive } \\
\text { strength (MPa) }\end{array}$} \\
\cline { 3 - 7 } & Initial set & Final set & $3 \mathrm{~d}$ & $28 \mathrm{~d}$ & $3 \mathrm{~d}$ & $28 \mathrm{~d}$ \\
\hline 340 & Qualified & 140 & 210 & 5.3 & 7.6 & 20.6 & 48.8 \\
\hline
\end{tabular}

\footnotetext{
* Corresponding author:604849392@qq.com
} 
Table 2 Technical indicators of Mixconverter

\begin{tabular}{|c|c|c|c|}
\hline Items & $\begin{array}{c}\text { Technical } \\
\text { indicators }\end{array}$ & Items & Technical indicators \\
\hline Color, odor & $\begin{array}{c}\text { Liquid, opaque, } \\
\text { odorless }\end{array}$ & Toxic & Non \\
\hline Densityg $/ \mathrm{m}^{3}$ & 1.10 & $\begin{array}{c}\text { VOC/VOS } \\
\text { contents }\end{array}$ & Non \\
\hline PH value & 11.5 & $\begin{array}{c}\text { Environmental } \\
\text { impact }\end{array}$ & Non/neutral \\
\hline Flash point & None & Cleaning method & $\begin{array}{c}\text { Flush (safe for } \\
\text { sewers) }\end{array}$ \\
\hline
\end{tabular}

\section{2. evaluation Performance testing research and}

\subsubsection{Concrete mix design}

According to the commonly used strength grades of highgrade cement concrete pavements, the concrete mix was designed and the benchmark concrete test piece M0 was formed based on $\mathrm{C} 40$ concrete. At the same time, the Mixconverter was added on a basis of $0.2 \%, 0.3 \%$ and $0.4 \%$ of the cement content per cube (denoted as M2, M3, M4) and the contents of cement, sand and stone materials were adjusted accordingly.

Table 3 Slump and strength tests results

\begin{tabular}{|l|l|l|l|l|l|l|l|}
\hline \multirow{2}{*}{ No. } & \multirow{2}{*}{ Slumpmm } & \multicolumn{3}{|c|}{ Compressive strength(MPa) } & \multicolumn{4}{c|}{ Flexural strength(MPa) } \\
\cline { 3 - 8 } & & $7 \mathrm{~d}$ & $14 \mathrm{~d}$ & $28 \mathrm{~d}$ & $7 \mathrm{~d}$ & $14 \mathrm{~d}$ & $28 \mathrm{~d}$ \\
\hline M0 & 50 & 31.2 & 42.6 & 45.5 & 3.43 & 4.25 & 5.15 \\
\hline M2 & 60 & 31.6 & 43.5 & 47.4 & 3.56 & 4.36 & 5.42 \\
\hline M3 & 60 & 33.6 & 46.5 & 49.8 & 3.76 & 4.76 & 5.62 \\
\hline M4 & 60 & 35.2 & 48.8 & 51.6 & 3.78 & 4.90 & 5.76 \\
\hline
\end{tabular}

It can be seen from Table 3 that with the concrete slump basically unchanged, the compressive strength and the flexural strength of the concrete has been increased on the 7th day, 14th day and 28th day due to the addition of Mixconverter, which signifies that Mixconverter reduces water consumption and enhances the strength.

The compressive strength of $\mathrm{M} 2$ test piece with $0.2 \%$ Mixconverter addition is slightly higher than that of M0, while the compressive strength of M3 and M4 test pieces with $0.3 \%$ and $0.4 \%$ Mixconverter addition has been increased by $7.7 \%$ and $12.8 \%$, respectively on the $7^{\text {th }}$ day and by $9.5 \%$ and $13.4 \%$ on the $28^{\text {th }}$ day compared with that of M0. And the flexural strength has increased by $9.6 \%$ and $10.2 \%$ on the $7^{\text {th }}$ day and $9.1 \%$ and $11.8 \%$ on the $28^{\text {th }}$ day, thereby indicating that the addition of Mixconverter to the concrete can significantly enhance the strength both in the early stage and in the late stage and the more the content, the more obvious the increase in strength. This is because Mixconverter participates in the hydration reaction during the concrete mixing process, which can promote the production of hydrated calcium silicate gel, so that a denser microstructure is formed inside the concrete, thereby improving the strength in the early stage.

\subsubsection{Compressive strength and flexural strength test}

The compressive strength and flexural strength tests were conducted in accordance with the specification [6]. A non-standard cubic test piece of $100 \mathrm{~mm} * 100 \mathrm{~mm} * 100 \mathrm{~mm}$ was used in the compressive strength test while a nonstandard prism test piece of $100 * 100 * 400 \mathrm{~mm}$ was used in the flexural strength. The compressive strength and flexural strength were tested on the $7^{\text {th }}$ day, $14^{\text {th }}$ day and the $28^{\text {th }}$ day. The test results are shown in Table 3 .
In addition, in the concrete curing process, Mixconverter can also maximize the hydration degree of the concrete, further improve the compactness of the concrete, and significantly increase the strength in the later stage.

\subsubsection{Cracking resistance performance test}

The flat plate method was used for the test in this paper with reference to the research results of Y. Kasai et al.[7, 8] for the test mold and the structure size was $600 * 900 * 800 \mathrm{~mm}$. Concrete was poured into the mold and after vibrating and smoothing, it was covered by plastic film. After $2 \mathrm{~h}$, a $40 \mathrm{~W}$ electric fan was used to blow air on the surface of the test piece for 24 hours. The initial cracking time was recorded and the number of cracks, the length and maximum width of the cracks were counted after the test. The average areas of cracks $a$, number of cracks per unit area $b$ and total areas of cracks $c$ were used to evaluate the cracking grade. The $a, b$ and $c$ were calculated per formula (1), (2) and (3), respectively. The cracking evaluation grade was divided into four grades, as shown in Table 4. 


$$
a=\frac{\sum W_{i} \cdot L_{i}}{2 N}\left(\mathrm{~mm}^{2}\right)
$$

Where $W_{i}$ denotes the largest width of the $\mathrm{i}^{\text {th }}$ crack, in $\mathrm{mm} ; L_{i}$ denotes the length of the $\mathrm{i}^{\text {th }}$ crack, in mm and $N$ denotes the total number of cracks.

$$
\begin{gathered}
b=\frac{N}{A} \quad\left(\text { number } / \mathrm{m}^{2}\right) \\
c=a \times b\left(\mathrm{~mm}^{2} / \mathrm{m}^{2}\right)
\end{gathered}
$$

Table 4 Crack grading

\begin{tabular}{|l|l|l|l|l|}
\hline \multirow{2}{*}{ Level } & I level & II level & III level & IV level \\
\cline { 2 - 5 } & $\begin{array}{l}\text { Meet 4 } \\
\text { conditions }\end{array}$ & $\begin{array}{l}\text { Meet 3 } \\
\text { conditions }\end{array}$ & $\begin{array}{l}\text { Meet 2 } \\
\text { conditions }\end{array}$ & $\begin{array}{l}\text { Meet zero } \\
\text { conditions }\end{array}$ \\
\hline $\begin{array}{l}\text { Grading } \\
\text { standard }\end{array}$ & $\begin{array}{l}\text { Only very fine cracks; 2) } \\
\left.\text { number } / \mathrm{m}^{2} ; 4: c<10 \mathrm{~mm}^{2} ; 3\right) b<10 \\
\text { num } c / \mathrm{m}^{2}\end{array}$ \\
\hline
\end{tabular}

Note: IV level cracking is the most serious.

Given the strength test results, flat plate anti-cracking tests were carried out on M0, M3, and M4, and a highpower microscope was utilized for continuous observation for 24 hours. During the test, it was found that the M0 test piece began to crack after 4 hours. After the test, the $a, b$ and $c$ were calculated, where a was $3.02 \mathrm{~m}^{2}$, b was 4.23 number $/ \mathrm{m}^{2}$, and $c 12.77 \mathrm{~mm}^{2} / \mathrm{m}^{2}$. And the cracking grade fell into II level. However, the M3 and M4 test pieces with Mixconverter addition showed no cracks on the surface during the test. In the meantime, it was also found that there was bleeding on the surface of the M0 test piece, but no bleeding occurred on the surface of M3 and M4. It can be seen that the addition of Mixconverter can obviously improve the plastic cracking performance of concrete. This is because the plastic shrinkage of concrete is mainly caused by the water loss rate of the concrete surface being greater than the bleedin grate. The addition of Mixconverter can reduce the occurrence of concrete bleeding, thereby effectively preventing the plastic shrinkage and cracking of the concrete.

\subsubsection{Chloride ion permeability resistance test}

As for the durability of concrete, in addition to the consideration of the water permeability, the damage to the concrete and the corrosion of steel bars caused by the penetration of chloride ions should also be considered $[9,10]$. For instance, when the concrete pavement freezes in snowy days in winter, deicing salt is often applied as it can react with the hydration products of cement to form easily soluble salt, and also react with the hydration products of calcium aluminate to form double salt $\left(\mathrm{C}_{3} \mathrm{~A} \cdot \mathrm{CaCl}_{2} \cdot 10 \mathrm{H}_{2} \mathrm{O}\right)$ of large expansibility, causing damages to the concrete pavement. When marine engineering concrete is corroded by chloride salts in seawater, it is also related to the penetration of chloride ions.

With reference to the Specification for Deterioration Prevention of Highway Concrete Structures (JTG/T B0701-2006), the simple and practical RCM method was used for measurement during the tests. The M3 test piece was chosen as the comparison test piece. The test results are shown in Table 5. Compared to the M0 benchmark concrete, the chloride ion diffusion coefficient of M3 concrete is significantly lowered and the chloride ion permeability resistance is evaluated as medium and low,

\begin{tabular}{|c|c|c|c|c|}
\hline Types & $\begin{array}{c}\text { Test } \\
\text { results } \\
\left(10^{-}\right. \\
\left.{ }^{9} \mathrm{~cm}^{2} / \mathrm{s}\right) \\
\end{array}$ & $\begin{array}{l}\text { Average } \\
\quad\left(\times 10^{-}\right. \\
\left.{ }^{9} \mathrm{~cm}^{2} / \mathrm{s}\right)\end{array}$ & $\begin{array}{c}\text { Power } \\
\text { (Coulomb) }\end{array}$ & $\begin{array}{c}\text { ASTM C } \\
1202-2008 \\
\text { Evaluation } \\
\text { results }\end{array}$ \\
\hline \multirow{3}{*}{ M0 } & 11.9 & \multirow{3}{*}{13.2} & \multirow{3}{*}{2029} & \multirow{3}{*}{ Medium } \\
\hline & 13.0 & & & \\
\hline & 14.6 & & & \\
\hline \multirow{3}{*}{ M3 } & 10.4 & \multirow{3}{*}{9.8} & \multirow{3}{*}{1261} & \multirow{3}{*}{ Low } \\
\hline & 9.4 & & & \\
\hline & 9.6 & & & \\
\hline
\end{tabular}
respectively according to ASTM C1202-94.

Table 5 Concrete chloride ion diffusion coefficient test results

\section{On-site application effect study}

In order to verify the actual application effect of Mixconverter, a $160 \mathrm{~m}$ road was paved on a highway in Guangdong Province for testing.

\subsection{On-site mix and construction}

The on-site construction benchmarks, mix ratios and performance of Mixconverter are shown in Table 6 and Table 7, respectively. During the construction and mixing process, it was found that the fresh concrete in the test road with Mixconverter featured homogeneity, good cohesion, good water retention, no segregation, a slump of $35 \mathrm{~mm}$ and well vibrated and compacted concrete.

Table 6 Mix ratio of cement concrete benchmark group

\begin{tabular}{|c|c|c|c|c|c|c|c|}
\hline $\begin{array}{c}\text { Cement } \\
(\mathrm{kg})\end{array}$ & $\begin{array}{c}\text { Sand } \\
(\mathrm{kg})\end{array}$ & $\begin{array}{c}\text { Stone } \\
(\mathrm{kg})\end{array}$ & $\begin{array}{c}\text { Water } \\
(\mathrm{kg})\end{array}$ & CNF-3 & $\begin{array}{c}28 \text { day } \\
\text { shrinkage } \\
(\%)\end{array}$ & $\begin{array}{c}28 \text { day } \\
\text { flexural } \\
\text { strength } \\
(\mathrm{MPa})\end{array}$ & $\begin{array}{c}28 \text { day } \\
\text { compressive } \\
\text { strength } \\
(\mathrm{MPa})\end{array}$ \\
\hline 361 & 662 & 1286 & 141 & 3.61 & 0.02825 & 5.59 & 43.3 \\
\hline
\end{tabular}


Table 7 Concrete mix ratio with Mixconverter

\begin{tabular}{|c|c|c|c|c|c|c|c|}
\hline $\begin{array}{c}\text { Cement } \\
(\mathrm{kg})\end{array}$ & $\begin{array}{c}\text { Sand } \\
(\mathrm{kg})\end{array}$ & $\begin{array}{c}\text { Stone } \\
(\mathrm{kg})\end{array}$ & $\begin{array}{c}\text { Water } \\
(\mathrm{kg})\end{array}$ & $\begin{array}{c}\text { Mixconverter } \\
(\mathrm{kg})\end{array}$ & $\begin{array}{c}28 \text { day } \\
\text { shrinkage } \\
(\%)\end{array}$ & $\begin{array}{c}28 \text { day } \\
\text { flexural } \\
\text { strength } \\
(\mathrm{MPa})\end{array}$ & $\begin{array}{c}28 \text { day } \\
\text { compressive } \\
\text { strength } \\
(\mathrm{MPa})\end{array}$ \\
\hline 361 & 662 & 1286 & 141 & 1.08 & 0.02455 & 6.24 & 48.0 \\
\hline
\end{tabular}

\subsection{On-site inspection}

Rebound tests were carried out on the front and side surfaces of the test road after construction. Test results are shown in Table 8. In addition, core samples were taken on the test road surface and the samples featured good aggregate grading, good mud wrapping, good compactness, and the splitting ultimate tensile strength is $3.87 \mathrm{MPa}$. The converted beam flexural strength is $6.07 \mathrm{MPa}$. In the process of testing the test road, it was found that there were no plate breaks, peeling, imprints, cracks or missing corners on the surface of the plate on the pavement.

Table 8 Rebound test results

\begin{tabular}{|c|c|c|c|c|c|c|c|c|c|c|c|c|c|c|c|c|c|c|c|}
\hline \multicolumn{2}{|c|}{$\begin{array}{l}\text { Rebound } \\
\text { hammer } \\
\text { model }\end{array}$} & \multicolumn{2}{|c|}{$\begin{array}{c}\text { ZC3-A } \\
\text { type }\end{array}$} & \multicolumn{5}{|c|}{$\begin{array}{l}\text { Test angle: } \\
\text { horizontal, up, down }\end{array}$} & \multicolumn{11}{|c|}{ Test surface status: side, surface, bottom, dry, wet, smooth, course } \\
\hline $\begin{array}{l}\text { Test } \\
\text { area }\end{array}$ & 1 & 2 & 3 & 4 & 5 & 6 & 7 & 8 & 9 & 10 & 11 & 12 & 13 & 14 & 15 & 16 & $\begin{array}{l}\text { Effective } \\
\text { mean N }\end{array}$ & $\begin{array}{l}\text { Carbonization } \\
\text { Depth }(\mathrm{mm})\end{array}$ & $\begin{array}{c}\text { Inferred } \\
\text { strength } \\
(\mathrm{MPa})\end{array}$ \\
\hline Side & 40 & 42 & 36 & 42 & 36 & 38 & 38 & 38 & 40 & 46 & 34 & 36 & 36 & 40 & 44 & 38 & 38.6 & 0 & 38.6 \\
\hline Front & 32 & 34 & 32 & 30 & 34 & 34 & 34 & 34 & 28 & 28 & 30 & 36 & 32 & 34 & 30 & 28 & 32.2 & 0 & 32.2 \\
\hline Front & 30 & 32 & 30 & 30 & 32 & 28 & 30 & 30 & 32 & 34 & 36 & 34 & 36 & 30 & 32 & 30 & 31.2 & 0 & 31.2 \\
\hline Side & 36 & 32 & 30 & 32 & 34 & 36 & 34 & 34 & 32 & 30 & 38 & 36 & 36 & 40 & 40 & 38 & 34.8 & 0 & 34.8 \\
\hline
\end{tabular}

The above on-site test results and the inspection results indicate that the addition of Mixconverter to the concrete can significantly improve the strength and cracking of concrete.

\section{Conclusion}

1) The application effect of Mixconverter is verified indoors through indoor compressive strength, flexural strength, crack resistance, and chloride ion permeability resistance tests. The test results show that the addition of Mixconverter can significantly improve the compressive and flexural strength of concrete. The expansion of plastic shrinkage cracking can be effectively prevented and the chloride ion diffusion coefficient can be obviously lowered.

2) The test road pavement further proves that the addition of Mixconverter to concrete can significantly improve the strength and cracking of concrete and it is worthy of promotion and application.

\section{References}

1. LIANG Junlin, WANG Hao, ZHANG Qing. Effect of Curing Temperature and Humidity conditions on Flexural Tensile Strength of Pavement Cement Concrete [J]. Journal of Highway and Transportation Research and Development, 2011, 28 (11): 32-38.

2. HE Xiaobing, SHEN Qiang. Early strength and fracture properties of PP fiber reinforced selfconsolidating concrete [J]. Huazhong Univ. of Sci. \& Tech. (Natural Science Edition), 2013, 41 (3): 115121.
3. WANG Jiliang, TIAN Bo, ZHANG Qing. Plastic Shrinkage Cracking Behavior of Pavement Cement Concrete at Early Age [J]. Journal of Highway and Transportation Research and Development, 2012, 29 (4): 1-6.

4. TANG Ming, FU Baiquan, SUN Xiaowei. Effect of Material Composition on the Fractal Characteristics of the Plastic Shrinkage Cracking in Concrete at Early Age [J]. Journal of Shenyang Jianzhu University (Natural Science), 2007, 23 (2): 258-262.

5. SHEN Aiqin, ZHU Jianhui, et al. Performance and Mechanism of Polymer Modified Superfine Cement for Microcrack Mending of Concrete Structure [J]. China Journal of Highway and Transport, 2006, 19 (4): 46-51.

6. JTG E30-2005, Testing Methods of Cement and Concrete for Highway Engineering [S]. Beijing: China Communication Press Co., Ltd., 2005.

7. LI Li, SUN Wei, LIU Zhiyong. A slab test of earlyage plastic shrinkage and cracking of high performance concrete [J]. Concrete, 2003 (12): 33-36

8. YUE Aijun, LIANG Junlin. Research on Mechanism and Prevention Measures of Plastic Shrinkage Cracking of Cement Concrete Pavement [J]. Journal of China \& Foreign Highway 2011, 31 (5): 55-58.

9. XU Chen, WANG Chuankun, JIN Weiliang. Interaction Effect of Chloride Attack and Carbonization in Concrete [J]. Journal of Building Materials, 2011, 14 (3): 376-380.

10. ZHANG Weiping, GUAN Xiaojun, REN Jiajun, et al. Experimental Study on Chloride Permeability of Concrete Surface-Treated with Epoxy Resin [J]. Journal of Building Materials, 2008, 11 (3): 340-344. 